\title{
Is the decisive issue in geoengineering debates really one of representation of nature?
}

Gaia against (or with?) Prometheus?

\author{
Sébastien DUTREUIL, Aix Marseille Univ, CNRS, Centre Gilles Gaston Granger, Aix-en- \\ Provence, France \\ $\underline{\text { Sebastien.dutreuil@univ-amu.fr }}$
}

\section{Acknowledgements}

I would like to warmly thank Laurent Bopp, Régis Briday, Amy Dahan, JeanBaptiste Fressoz, Hélène Guillemot, Marion Lemoine and Timothy Lenton for their review of this text and for the fascinating and useful discussions we had on this text.

Geoengineering has long been considered a science fiction solution designed by climate wizards - physicists, who inherited Cold War era, tinkering in the shadows with their demiurgic designs. Presented in this way, these Promethean solutions are likely to be rejected by the large majority. The most common reaction to these techniques is thus rejection, based on the feeling that they are based on a pathological conception of nature, the Earth and the relationship that humans must maintain with it. But important, albeit recent, developments seem to change how these techniques are presented, and could thus change the degree and mode of adherence to them, without changing anything about what these techniques are and the dangers they represent. This paper analyses two discourses in favour of the deployment of geoengineering techniques: the Promethean discourse and the Gaian or Earth system discourse. Both hinge on radically opposed conceptions of nature and of the Earth which leads me to question the idea, however classically accepted, that what is at stake in the geoengineering debate is first and foremost a question of the representation of nature.

It is common to distinguish two types of geoengineering techniques, those aimed at modifying the Earth's albedo on a large scale - the so called 'Solar Radiation Management' or SRM techniques - via, for example, the injection of sulphur particles into the stratosphere. And those aimed at capturing atmospheric carbon, the so called Carbon Dioxide Removal (CDR) techniques, such as afforestation or bio-energy production associated with $\mathrm{CO} 2$ storage resulting from biomass combustion. ${ }^{1}$ Rather than an opposition between albedo-modifying and chemistrymodifying techniques, it would probably be more appropriate to distinguish between techniques with an immediate global effect and those with a local scope, the two

\footnotetext{
${ }^{1}$ In certain circumstances and at the cost of precise argumentative work, it would be possible to argue that what applies to SRMs applies to certain CDR techniques deployed in certain ways. We can make some suggestions, even if a much more detailed work would have to be done. First, the scale of deployment required for the effectiveness of negative emission technologies could blur the classic distinction between large-scale modification of the Earth's albedo (SRM) and the development of local forest gardens within state boundaries (CDR). Secondly and above all, within the discourse space, the discourses legitimizing SRM on the one hand, those supporting CDRs on the other, may be part of the same dynamic, since both stress the urgency to act and the impossibility of stabilizing the climate in a reasonable state in the absence of the use of these technologies - the two discourses therefore pose the same risk of a moral hazard. Moreover, the two discourses are by no means incompatible, and can converge. Some propose to multiply and diversify the arsenal of techniques to limit the risks inherent in each one, to modulate the local-regional effects that a particular technique could have, or to mobilize them at different times.
} 
distinctions not systematically overlapping ${ }^{2}$. Throughout the text, I most often use geoengineering to implicitly refer to immediately global changes, but no doubt one of the aims of the text is to re-examine the categories of geoengineering.

\section{The Promethean Discourse}

The scales at play in geoengineering, and particularly in the deployment of SRM techniques, whose effects are systemic, inevitably raise concerns: what Promethean dream has struck people to the point of playing the role of demiurges and wizards with the entire planet? The most brilliant form of such a critical position was developed by Clive Hamilton, along with Fleming's original historical work ${ }^{3}$. Hamilton documented the historical origins and ideological foundations of a trend defending the application of geoengineering to solve the contemporary climate problem: contemporary physicists, heirs of the Manhattan programme and the Cold War, are going back to ideas of climate modification once conceived for military purposes. The Promethean discourse conveyed by these physicists aim at legitimizing geoengineering techniques and is based on a particular epistemology, ontology (or conception of nature) and anthropology.

1. History of Geophysics: A Reconfiguration of the Earth Sciences during the Cold War

To understand this epistemology, ontology and anthropology, it is necessary to look back at some of the decisive transformations in the Earth Sciences that took place during the Second World War and the Cold War. The contemporary state of the geosciences - both its scientific practices and the conceptions of the Earth that underlie them - owes much to these transformations. During this period, geophysics, conceived as a particular style of research within the Earth Sciences, mobilizing physical practices and theories to understand how the Earth works, experienced an unprecedented growth. It is this development that has given rise to the two contemporary paradigms that structure the Earth Sciences as a whole: modern climatology and plate tectonics. This development of geophysics is mainly the result of a transition in which military patronage takes precedence over traditional sources of funding for geology and Earth sciences, namely universities, national funding agencies, and the mining and petroleum industries ${ }^{4}$. Meteorology, seismology, physical mapping of the seabed and physical oceanography are all disciplines whose developments have been guided by strategic and military imperatives and logic indeed this knowledge plays decisive roles: the monitoring of nuclear tests, submarine navigation aids and elaboration of flight plans ${ }^{5}$. It was in this context that the first reflections on weather modifications began to emerge: fog dissipation to facilitate planes' landing, precipitation control to intensify rains in Vietnam and

\footnotetext{
${ }^{2}$ Régis Briday, 'Le discours de la promesse chez les promoteurs de l'ingénierie climatique' (2019), Socio, 12, 133 - 157 .

${ }^{3}$ Clive Hamilton, Earthmasters : playing god with the climate, 2013, Yale University Press. Roger J. Fleming, Fixing the sky : the checkered history of weather and climate control, 2013, Columbia University Press, New York.

${ }^{4}$ Ronald E. Doel, 'Constituting the Postwar Earth Sciences The Military's Influence on the Environmental Sciences in the USA after 1945' (2003), Social Studies of Science, 33, 5, 635-666. ${ }^{5}$ Doel (2003) ; Jacob D. Hamblin, Arming mother nature : the birth of catastrophic environmentalism, 2013, Oxford University Press, Oxford ; Simone Turchetti and Peder Roberts, The surveillance imperative : geosciences during the cold war and beyond, 2014, Palgrave Macmillan, New York.
} 
bogged roads to slow the progress of enemy troops ${ }^{6}$. The development of geophysics has brought about a lasting transformation in Earth Science practices: the importance of interpretative and qualitative work based on field observations in geology is replaced by field instrumentation, continuously and quantitatively monitoring different variables ${ }^{7}$.

\section{The Ontology of Prometheans}

The Promethean discourse supporting geoengineering inherits the conceptions of the Earth that were developed during this key period. Both plate tectonics and climatology are based on a physical conception of the Earth: the solid Earth is divided into a set of plates with geometric, mechanical and thermodynamic properties. Likewise the climate system is defined in such a way that all the variables, tools and theories of fluid mechanics and thermodynamics are entirely sufficient to account for it. This is particularly striking in the representation of the climate system given by a famous article ${ }^{8}$, which is also known to have been one of the first to raise the question of the relevance of deploying geoengineering techniques to stabilize the climate. The absence of other types of entities, such as chemical, biological and human variables is particularly striking here, and exemplary of what physical climatology was. Doel highlights how the two deep roots of environmental knowledge, one biological and ecological, the other rooted in the geophysics of the Cold War, lived in separate worlds ${ }^{9}$. It is indeed this physical conception of the globe that underlies today the 'Promethean' analyses of geoengineering, comparing the different technical solutions, sometimes on the sole basis of radiative budgets.

\section{An Epistemology Based on Quantitative Prediction Using Models}

The Promethean discourse inherits not only a physical ontology of the globe but more broadly from the epistemological transformations of the Cold War. The Promethean epistemology of control and prediction is thus rooted in cybernetics, the science of systems, information, feedback, thermostats, regulation and control ${ }^{10}$. The possibility of controlling the climate also makes the epistemological assumption that we fully understand the climate system, and that we can therefore quantitatively predict its behaviour and the evolution of its various variables following an intervention on it:

'For Von Neumann, weather modification lay somewhat further away in the future, because it was linked in his mind to the yet to be developed long-range

\footnotetext{
${ }^{6}$ Fleming, Op. Cit.

${ }^{7}$ Naomi Oreskes and Ronald E. Doel, 'Physics and chemistry of the Earth', in Mary J. Nye, The cambridge history of science. Vol. 5 : modern physical and mathematical sciences, 2008, Cambridge University Press, 538-557.

${ }^{8}$ William W. Kellogg and Stephen H. Schneider, 'Climate stabilization : For better or for worse ?' (1974), Science, 186, 4170, 1163-1172.

${ }^{9}$ Op. Cit.

${ }^{10}$ Peter Galison, 'The ontology of the enemy : Norbert Wiener and the cybernetic vision' (1994), Critical inquiry, 21, 1, 228-266.
} 
forecasting (...). For Von Neumann, prediction and intervention were closely interlinked. ${ }^{11}$

The close links between a technical intervention and quantitative prediction using models are still particularly striking today, as is the importance given to epistemological issues, rather than normative ones. It is particularly significant in this respect that anthropological, moral and political criticism has had little impact on the proponents of Promethean discourse. On the other hand, the latter took the very accurate epistemological criticism developed by Alan Robock and his colleagues much more seriously. Robock and his colleagues highlighted the technical specificity of geoengineering solutions: these techniques cannot be tested before they are deployed on a large scale, and a large-scale deployment could have unpredictable catastrophic effects ${ }^{12}$. The only epistemic resources available to understand these techniques are therefore models: past analogues (such as the Pinatubo explosion and the consequences of the subsequent aerosol dispersion); local experiments (ie scale models); or numerical simulations based on complex climate models on which 'numerical experiments' are performed. From there, the whole arsenal of arguments highlighting the epistemic limits of the models can be deployed. This epistemological criticism has reached, far more than normative criticisms, the proponents of Promethean discourse, who have gathered to respond to $\mathrm{it}^{13}$.

\section{An Anthropology of the Control and Mastery of Nature}

The epistemology and ontology of the Prometheans are finally accompanied by an anthropology that takes up the main themes of modernity, according to which humans have the role of controlling an external nature. The deployment of planetary techniques is inscribed in an untroubled continuity with the technical mastery of local and regional environments deployed so far: 'We've engineered every other environment we live in, why not the planet?'14.

Hamilton points out that the important divide is neither religious, nor political, nor the result of a particular affection for the environment or ecology:

'The divide is between Prometheans and Soterians, a technocratic rationalist worldview confident of humanity's ability to control nature, against a more humble outlook suspicious of unnatural technological solutions and the hubris of mastery projects.'

According to the most radical positions, only scientists who understand the physics of climate and how these techniques work should have the right to express themselves.

The main Promethean argument for the deployment of geoengineering (especially SRM techniques) is then based on technical and economic rationality: these techniques are simple, work, and are extremely inexpensive to implement (with respect to the damages caused by climate change or the cost required to reduce greenhouse gas emissions). The short-circuiting of democratic debates by technical

\footnotetext{
${ }^{11}$ Chunglin Kwa, 'The rise and fall of weather modification : changes in american attitudes toward technology, nature, and society' in Clark A. Miller and Paul N. Edwards (Eds), Changing the atmosphere : expert knowledge and environmental governance, 2001, The MIT Press, 141.

12 Alan Robock et al., 'A test for geoengineering' (2010), Science, 327, 5965, 530-531.

${ }^{13}$ Douglas G. MacMynowski et al., 'Can we test geoengineering ?' (2011), Energy \& Environmental Science, 4, 12, 5044-5052.

${ }^{14}$ Lowell Wood, quoted by Hamilton $O p$. Cit.
} 
solutions devised by a handful of engineers is seen as a virtue of geoengineering and not as one of its problems.

5. The Contemporary Importance of the Promethean Branch... and its philosophical criticism

This Promethean discourse supporting geoengineering is a real and concrete discourse, as documented by Hamilton and Fleming (with its actors, institutions, financial support, promotion methods, etc). The demiurgic nature of this discourse is one of the reasons for the taboo that has prevailed on geoengineering since the 1970 s - it is this same demiurgic dimension that is still sufficient for many to discredit geoengineering as a whole. The lifting of this taboo is generally attributed to two important events: the publication of an article by Paul Crutzen on the subject ${ }^{15}$, winner of the Nobel Prize in chemistry and the publication of a report by the highly respected Royal Society ${ }^{16}$. The lifting of this taboo has led to the creation of a 'geoclique': a handful of scientists working on the issue, sometimes over a long period of time, and meeting between themselves from one symposium to another. The most representative and characteristic positions of Promethean discourse have often been held by scientists from the Lawrence Livermore National Laboratory, where the legacy of the Cold War is particularly striking.

Although it should be evident at the end of this section, the following point should be emphasised: the structuring of debates, resulting from a reaction of rejection of the Promethean dream of geoengineering, gives a very central place to philosophical questions about how we represent nature (ontology), the knowledge we can have about it (epistemology) and the place that humans occupy in it (anthropology). Put simply, what is deemed wrong with geoengineering following the most classical reaction is that it is ultimately based on a questionable conception of nature and a pathological representation of the relationships between humans and nature, inherited from physics and modernity.

I would like to show that if reducing discourses in favour of geoengineering to the Promethean approach alone makes it possible to identify an important target - and, undoubtedly, easy to defeat - it does, however, prevent one from seeing the emergence of other discourses, also favourable to research and to a possible moderate deployment of these techniques. However, these other discourses have the important property of no longer immediately conveying this imaginary of domination of nature by apprentice-wizard and are therefore more likely to win the support of a previously sceptical public.

\section{The Gaian Discourse of the Earth System}

By focusing on the Promethean discourse, insufficient attention has been paid to the fact that some important actors who have contributed to the recent favourable development of debates on geoengineering present themselves with an epistemology, an ontology and an anthropology that are completely at odds with that of the Prometheans. These are based on a conception of the Earth inherited from the Gaia hypothesis.

\footnotetext{
${ }^{15}$ Paul J. Crutzen, 'Albedo enhancement by stratospheric sulfur injections : a contribution to resolve a policy dilemma ?' (2006), Climatic change, 7 , 3, 211-220 .

16 The Royal Society, Geoengineering the climate : science, governance and uncertainty, 2009, The Royal Society, London.
} 


\section{History of the Gaia Hypothesis and Earth System Science: A Holistic and Biologizing Turnaround after the 1980s}

The Gaia hypothesis, developed in the 1970s by Lovelock (and Margulis), proposed a new conception of the Earth as the complex system comprising living beings and the abiotic environment with which they interact ${ }^{17}$. The emergence of this new conception of the Earth, correlated with 'global changes' (climate change, ozone hole), underpinned a significant institutional effervescence, in the United States and on an international scale, in the $1980 \mathrm{~s}^{18}$. This effervescence has led to the establishment of 'Earth System Science' and the institutionalization of the International Geosphere Biosphere Programme (IGBP), an international research programme on global change.

It is necessary to underline a singular aspect of the IGBP, which is historically inherited from Gaia: the main ambition of this institution (and of the Gaia hypothesis) must be analysed - at least this is the thesis I defended ${ }^{19}$ - as a philosophical ambition. I have indeed shown that the scientific practice underlying the development of Gaia and the Earth System Science of the IGBP is philosophical in nature: it is a matter of making conceptual efforts to change our representation of the Earth. This is what the Director of the IGBP said very well in the late 1990s, at a time when the institution's great effort to synthesize was being undertaken:

'What is the nature of the Earth? The challenge for IGBP over the next three years is to make meaningful contributions directed towards answering this question'. ${ }^{20}$

And the most visible productions of the IGBP are the development of new normative concepts articulating issues of representation of the Earth with political issues: the Anthropocene ${ }^{21}$, the idea of tipping point ${ }^{22}$, the planetary limits ${ }^{23}$, and more recently the hothouse Earth ${ }^{24}$. Gaia, IGBP and Earth System science therefore have as their main function to produce normative concepts to rethink the Earth and nature anew - hence the fact that the stakes of Latour's analysis of Gaia are at the level of those of a philosophy of nature ${ }^{25}$.

Historically considered, Gaia and the Earth system have made an epistemological transition similar to that described in the first section. The conception of the Earth inherited from Gaia and now called 'Earth System' thus reverses the ontology, the epistemology, and the anthropology of the Prometheans : a reductionist, physicalist geophysics advocating an ideal of control during the Cold

\footnotetext{
${ }^{17}$ James E. Lovelock, 'Gaia as seen through the atmosphere' (1972), Atmospheric Environment, 6, 579-580; James E. Lovelock and Lynn Margulis, 'Atmospheric homeostasis by and for the biosphere : the Gaia hypothesis’ (1974), Tellus, 26, 1-2, 2-10.

${ }^{18}$ Sébastien Dutreuil, 'Gaïa : hypothèse, programme de recherche pour le système Terre, ou philosophie de la nature?’ (2016), PhD Thesis, Université Paris 1 Panthéon-Sorbonne, Paris.

${ }^{19}$ Dutreuil, Ibid.

${ }^{20}$ Will Steffen, 'How well do we understand the nature of Earth ?' (1998), IGBP Newsletter, 34, 7.

${ }^{21}$ Paul J. Crutzen, 'Geology of mankind' (2002), Nature, 415, 23.

22 Timothy M. Lenton, et al., 'Tipping elements in the Earth's climate system' (2008), Proceedings of the National Academy of Sciences, 105, 6, 1786-1793.

${ }^{23}$ Joan Rockström et al., 'Planetary boundaries : exploring the safe operating space for humanity' (2009), Nature, 461, 472-475.

${ }^{24}$ Will Steffen et al., 'Trajectories of the Earth System in the Anthropocene' (2018), Proceedings of the National Academy of Sciences, 115, 33, 8252-8259.

${ }^{25}$ Bruno Latour, Facing Gaia : eight lectures on the new climatic regime, 2017, Polity Press.
} 
War was thus partly replaced from the 1970s and 1980s by a holistic science of the Earth System, biologizing and concerned with global environmental issues ${ }^{26}$.

\section{The Ontology of Gaia and the Earth System}

The Earth system conception supported by the IGBP has, in recent decades, highlighted two important elements against purely physical conceptions of climate (which originally underpinned the IPCC's work) ${ }^{27}$. It first pointed out the importance of the effects of life on global changes and thus contributed to making the idea of global changes more complex by extending it beyond pure climate physics to include biodiversity and global biogeochemical cycles. The institutional effects of the Earth system discourse, for example, have led to the consideration of the effect of living organisms on the climate within physical climate models. Second, the sciences of complexity and chaos have replaced cybernetics as a framework for analysing the Earth as a system. This has had the effect of developing the idea that the Earth system could have more non-linearities than previously thought and that abrupt or catastrophic transitions could occur from certain thresholds: this is the central idea of tipping points, which then underlies the conception of planetary boundaries and the history of the Earth of the Anthropocene.

More broadly, Gaia and the Earth system have often been presented as being in philosophical opposition to the conceptions of nature inherited from modernity. Lovelock has constantly fought against the metaphor comparing the Earth to a spaceship of which humans would be the engineers. Schellnhuber, central theorist of the IGBP and one of the most influential contemporary climatologists, describes the sciences of the Earth system as Copernican revolution, given the philosophical upheavals they operate ${ }^{28}$. The level of stakes and the upheavals brought to our conceptions of life and nature led Latour to compare Lovelock to Galileo.

\section{The Epistemology of the Earth System Inherited from Complex Systems}

The epistemology of the Earth System science has been largely influenced, if not determined altogether, by that of the complexity sciences. Earth system science thus share with the complexity sciences two important epistemological features: a transdisciplinary ambition, and a questioning of our ability to predict the behaviour of the system studied.

The discourse that led to the creation of Earth System Science were thus based on the idea that it was necessary to go beyond geophysics alone. Precisely because the Earth system involves interactions between parts and processes that belong to different established disciplines (ecology, geochemistry, oceanography, climate physics, hydrology, soil studies, etc), its study is necessarily based on a science that transcends and integrates these different disciplines.

\footnotetext{
${ }^{26}$ E.g. Timothy M. Lenton, Earth system science: A very short introduction, 2016, Oxford University Press, Oxford. On the relationship of historical continuity between the conception of the Earth system and the epistemology of the Cold War, see Amy Dahan, 'Putting the Earth System in a numerical box? The evolution from climate modeling toward global change", Studies in History and Philosophy of Science Part B : Studies in History and Philosophy of Modern Physics' (2010), 41, 3, 282-292; Mathias Heymann and Amy Dahan Dalmedico, 'Epistemology and Politics in Earth System Modeling : Historical Perspectives' (2019), Journal of Advances in Modeling Earth Systems.

${ }^{27}$ Dahan, 2010, op. cit. ; Dutreuil, 2016, Op. cit.

${ }^{28}$ Hans Joachim Schellnhuber, 'Earth system analysis and the second Copernican revolution' (1999), Nature, 402, p. C19-C 23.
} 
The sciences of chaos and complexity have called into question the possibility of quantitative prediction: sensitivity to initial conditions, the phenomena of bifurcation prevent the quantitative prediction of the behaviour even of certain simple and deterministic systems. Earth system science inherits these traits from the complexity sciences and have highlighted several elements limiting our prediction capabilities, in addition to the feedback and non-linearities of the Earth system. Thus, the expansion of objects beyond the sole physics of climate and, in particular, the consideration of the effects of living beings on the Earth system, introduce obstacles to prediction: the evolutionary and ecosystem trajectories of the living are indeed difficult to predict. In addition, the Anthropocene highlighted the radically new nature of the current situation of the Earth system, modified by human activities: we are in a situation for which no past natural analogue exists, and the absence of an analogue would reduce our predictive capacities. All these elements have put a strong strain on the IGBP which precisely presented itself as a scientific institution enabling humanity to predict global changes and their effects - the successor programme to the IGBP has this ambition in its name: Future Earth.

It is also significant to note that the central epistemological innovation for Earth system modelling is the development of a new type of model, the so-called 'intermediate complexity models' (EMICS). These have been developed to 'demonstrate the plausibility of feedback processes; they are not generally used as predictive tools, ${ }^{29}$. These models have a much lower spatial resolution than conventional climate models, which makes it possible to allocate the computational power thus recovered to the modelling of many processes and many interactions between these previously unaccounted for processes - and it is these models that have done the most to highlight the non-linearities of the Earth system.

The 'tipping points' of the Earth system plague our ability to predict the system's behaviour, which is always susceptible to abrupt transitions and surprises. Therefore, the main epistemic ambition can no longer be to quantitatively predict the trajectory of the Earth system. The relationship that Earth System Science envisions with the future is the detection of 'early warning signals ${ }^{30}$, those small oscillations and disturbances that can be observed in a system when a catastrophic transition is imminent, and that can often only be observed when it is too late and the system is already irreversibly committed to the transition ${ }^{31}$.

\section{Anthropology of the Gaians: The Care of the Entities to which we are Linked}

Finally, the anthropology of the discourse of the Earth system is presented as being at odds with the modern anthropology and philosophy of nature. Humans are no longer considered as external to nature but as an integral part of the Earth system. And they must seek no longer to become masters of nature but to cooperate with the entities of the Earth system to which they are connected.

Gaia's development is contemporary with discoveries revealing the effects of human activities on global changes. In the same movement, we discovered the

\footnotetext{
${ }^{29}$ Will Steffen et al., 'Global change and the earth system : a planet under pressure' (2004), Springer, Berlin, 279.

${ }^{30}$ Timothy M. Lenton, 'Early warning of climate tipping points' (2011), Nature climate change, 1, 4, 201-209.

${ }^{31}$ For the sake of the distinction with the Prometheans epistemology I am here certainly overstating the position of many Earth system scientists. Although it is clear that the « complexity » and « tipping points » hinders our ability to quantitatively predict the detailed behaviour of the system, certain trends remain predictable
} 
extent of the effect of the living on the geological environment: the chemical composition of the ocean and atmosphere or the Earth's climate, which were considered purely physico-chemical phenomena, are partly influenced by the metabolic activity of the living and by the effect of humans on the global environment. It is the recognition of these effects that has given rise to the creation of a new object, made up of all living beings and the environment with which they interact. As a recent extension of Gaia, for some, the Anthropocene has contributed to a conception of the Earth, its history and the history of humans that breaks with the important legacies of modernity that came from the constitution of geology and that of the social sciences in the 19 th century ${ }^{32}$. Human institutions have a material footprint that is part of the Earth system. The effects of the Anthropocene discourse, showing the superposition of geological history and human histories, the inclusion of humans in the Earth system, and thus the interactions between domains of the world previously considered independent of each other, have been such that they have, if not completely undermined the methodological bases on which social sciences have been built since the 19th century, at least reshuffled the paradigms that have structured the social sciences in recent decades ${ }^{33}$.

The continuity of humans with the living, chemistry, air and water of the Earth system has been correlated with a shift in metaphors to consider our relationship with the planet, from the field of mechanics to the biomedical field: no more control of the Earth spaceship handled by engineers, now the "care" of Gaia is provided by scientists at the bedside of the Earth system. The theme of caring for the planet is thus omnipresent in this literature: from Lovelock, constantly recalling his work as a chemical engineer in the biomedical field when it is a question, as in the title of one of his books, to develop 'a medicine for ailing planet' ${ }^{34}$, to Schellnhuber representing the scientist of the Earth system, actor of a Copernican revolution, as a surgeon examining the planet ${ }^{35}$.

\section{The Recent Emergence of the Gaian discourse Supporting Geoengineering}

The conception of the Earth system reverses the epistemology, the ontology and the anthropology of the Prometheans. It emerged during the reflections on the global environment in the 1970s, before being endorsed and celebrated by international institutions, environmental NGOs and activist movements that have worked to document the extent of global changes and to alert to its dangers. We would therefore have every reason to expect that Gaia and the Earth system would be used to vigorously oppose geoengineering, counterbalancing the Promethean discourse. It is true that the complexity of the Earth system has been used to criticise the very possibility of geoengineering - how can we hope to intervene rationally on

\footnotetext{
32 Dipesh Chakrabarty, 'The climate of history : four theses' (2009), Critical Inquiry, 35, 2, 197 222.

${ }^{33}$ Christophe Bonneuil and Jean-Baptiste Fressoz, The shock of the Anthropocene: the Earth, history and us, 2016, Verso; Pierre Charbonnier, 'Généalogies de l'anthropocène: la fin du risque et des limites' (2017), Annales, Histoire, Sciences sociales, 2, 301-328.

${ }^{34}$ James E. Lovelock, Gaia : medicine for an ailing planet, 2005 (1991), Gaia Books, London.

35 1999, Op. cit.
} 
such a complex and unstable system ${ }^{36}$ ? But what is striking above all is precisely that certain actors, most at the heart of the development of the Gaian and systemic conception of the Earth, have in fact supported geoengineering ${ }^{37}$.

Paul Crutzen, who initiated the concept of the Anthropocene, is considered to be the key actor who liberated the taboo on geoengineering with his 2006 article. James Lovelock is also an important player in this recent period. He has proposed new technical solutions such as the artificial mixing of the oceans ${ }^{38}$ and supported existing thinking on geoengineering in his best-selling book, The Revenge of Faia $^{39}$. It is therefore no coincidence that white and black daisies are found on the main cover of the Royal Society's famous report, in reference to Gaia's iconic model: Daisyworld. These positions held by Lovelock are not new. At the very heart of Gaia's development in the 1960s, in a confidential report written for Shell by the chemist and consultant, there were already proposals such as the possibility of asphalting large areas of desert in order to prevent a global glaciation.

On what argumentative grounds can the Gaian discourses of geoengineering be based?

The complex and unpredictable nature of the Earth system's tipping points certainly hinders the possibility of quantitative and precise control and monitoring of the Earth. But at the same time, it considerably increases the emergency for action. The rationale behind the recent geoengineering proposals is based on the non-linear nature of the Earth system. In the face of the emergency and concern to abruptly switch the system, it would be necessary to quickly deploy these techniques to prevent the worst ${ }^{40}$. The ontology and epistemology of the Earth system are therefore not doomed to call into question the deployment of geoengineering techniques, on the contrary, they can support them, certainly by influencing the anthropological scope of these techniques:

'Systems theory suggests that complex systems can never be managed; they can only be perturbed, and the outcomes observed. Furthermore, many of these outcomes will likely be unpredictable, even with a vast amount of information on the system, leading to unintended and potentially severe consequences.' 41

\footnotetext{
${ }^{36}$ Mike Hulme, Can science fix climate change, 2014, Polity, Cambridge, UK ; Hamilton, 2013, Op. Cit.

${ }^{37}$ More detailed historical and sociological work should be done here on the relationships that all IGBP and Future Earth actors have with geoengineering. My objective here is not to show that proponents of Earth system conception will systematically be advocates and supporters of geoengineering (clearly they are not) e.g. Hans Joachim Schellnhuber, 'Geoengineering: the good, the MAD, and the sensible' (2011), PNAS, 108(51), 20277-20278. Rather, my aim is here to highlight the fact that epistemology, ontology (or Earth conception), anthropology, imaginaries and metaphors of Gaia/IGBP speeches have already been mobilized to support the deployment of geoengineering and will most likely lead to the rise of a new discourse legitimizing geoengineering.

${ }^{38}$ James E. Lovelock and Chris Rapley, 'Ocean pipes could help the Earth to cure itself' (2007), Nature, 449, 7161, 403-403.

39 James E. Lovelock, The revenge of Gaia, 2006, Penguin Books, London.

${ }^{40}$ For a critical analysis of this position, see Timothy M. Lenton, 'Can emergency geoengineering really prevent climate tipping points?' in Jason J. Blackstock and Sean Low, Geoengineering our Climate? Ethics, Politics, and Governance, 2018, Routledge, London.

${ }^{41}$ Steffen et al. 2004, Op cit., 286.
} 
If we cannot predict the consequences of our technical interventions, we must resort to 'adaptive management', as the expression goes, consisting in acting, observing the consequences, and then modifying our actions ${ }^{42}$.

How can we even think about the possibility of Gaian geoengineering if we consider the inclusion of humans in the Earth system as a moment of environmentalist awakening that challenges the modern idea of mastering an external nature? But to think that this anthropological shift would fundamentally call into question the possibility of technical action on the Earth system is to be blind to the historical origins of this same shift. We must return to the details of Gaia's development to understand that Lovelock's inscription of humans in Gaia is correlative to a shift in our conception of anthropogenic pollution, and more generally to the effects that humans have on the Earth system. Pollution and these effects lose their character of anthropological exception to become a natural phenomenon. Just as bacteria contributed to oxygenating the atmosphere 2 billion years ago, so human industries metabolize and excrete products in Gaia ${ }^{43}$. It is the same framework of reflection, that of the 'earthsystem' against the physics of the Prometheans, that leads Oliver Morton to argue that we have already deployed large-scale geoengineering techniques by deliberately intervening on the global nitrogen cycle during the transformations of agricultural models in the 20th century - climate change techniques would then only prolong this action. ${ }^{44}$

Humans are no longer omniscient, omnipotent mechanics outside Gaia, but they can still be doctors, with an unconventional medical tendency who 'help the Earth to cure itself'. This is the title of Lovelock and Rapley's article that proposed to have concrete pipes in the oceans to artificially mix the oceans and increase plankton productivity.

The technical and economic rationality that underpinned the Promethean discourse ('it works and it's cheap!') is giving way to aesthetic arguments highlighting the beauty that can be found in taking care of the planet we inhabit:

'It may be a matter of aesthetics. The conflict between the fear and power chambered together in the heart of the sublime becomes much more uncomfortable if no beauty is experienced (...). I can see arguments for geoengineering based on compassion, on duty and on virtue. In the end, though, should there not - must there not - be an argument that stems from beauty? If there is no beauty, merely power, can the technological traditions of titans be anything other than monstrous? ${ }^{45}$.

\footnotetext{
42 Ibid. 295 sq. It should be noted that the passages quoted here do not advocate the use of geoengineering. I am presenting them to emphasize that a gaian management of the Earth system would be envisaged differently from a precise and quantitative control of a physical system by the Prometheans.

${ }^{43}$ Sébastien Dutreuil, 'James Lovelock, Gaïa et la pollution : un scientifique entrepreneur à l'origine d'une nouvelle science et d'une philosophie politique de la nature' (2017), Zilsel, 2 , 1961.

${ }^{44}$ Oliver Morton, The planet remade : how geoengineering could change the world, 2016, Princeton University Press, Princeton. The argument of Morton's masterful book is obviously not limited to this one; nor could Morton's book be summarized as a defence of geoengineering based on conceptions inherited from Gaia. It should be read in its entirety to appreciate the finesse of the arguments in each of the scientific, philosophical, historical and political registers.

${ }^{45}$ Morton, Ibid., 338. As we read these lines, we remember the analysis of Jean-Baptiste Fressoz ('L'anthropocène et l'esthétique du sublime', http://mouvements.info/sublime-anthropocene/), stressing that the Anthropocene is an aesthetic concept - reactivating the aesthetics of the sublime before being a scientific concept, useful to geologists and stratigraphers
} 
III. Conclusion and Perspectives: What does Gaia or the Earth System Change in the Debates on Geoengineering?

In recent years, marked by environmental issues, theories of the Earth and philosophies of life, philosophical anthropologies of nature have developed on the hypothesis that we cannot face environmental and climate crises without thoroughly re-examining the categories inherited from modernity and allowing us to think about our relationship to the natural world. Geoengineering is certainly the subject that has put our conceptions of nature under tension in the most paroxysmal way. And the most common hypothesis is that the most fundamental issues, which should be the main entry point for debates on geoengineering, are precisely these general conceptions of nature. The analysis proposed in this article invites us to question this hypothesis. In addition to the Promethean discourse based on a physical and reductionist conception of nature, a second discourse supporting geoengineering has recently been added, based on a holistic and biologising conception of the Earth, developed during the decades of the environment and global change. However, if it is true that a philosophy of nature based on an epistemology, an ontology and an anthropology explicitly presented as being in radical opposition to those of the Prometheans can also be used to defend the idea that geoengineering techniques could and should be deployed - certainly in ways that would differ in some aspects from those envisaged by the Prometheans - then there is good reason to question whether it is indeed our philosophical representations of nature that are the most decisive for the debates on geoengineering.

In addition to what has been indicated in the text, it is important here to underline the non-univocal nature of the relationships between a given scientific work, a philosophy of nature or of the Earth and a position on geoengineering. Not all scientists working in climate physics necessarily endorse the Prometheans philosophy of nature and not all are advocates of geoengineering, far from it. ${ }^{46}$ Symmetrically, not all biogeochemists and Earth system scientists necessarily embrace the Gaian philosophy of nature and not all defend the deployment of geoengineering techniques.

The argument I would like to defend is in no way that the philosophical work carried out to question our representations of nature is useless or secondary in general, but simply to point out that in the case of geoengineering, we may have overrated the importance of this philosophical work. Or rather, what I would like to say is that if we start by taking these philosophical questions seriously, and if we also take an interest in the (recent) sociological mapping of the debate, we are led, in a second step, to conclude either that philosophical issues are perhaps less central than they seem, or that they have a different role than the one they are spontaneously assigned. We must first gather what has been said to highlight the argument, before moving on to the perspectives.

It is true that the argumentative forces and the modalities under which Gaian earth system scientists support geoengineering differ from that of the Prometheans in at least three respects. First, Gaia is more alive and diversified than the simple physics of the spaceship. For Gaians we must now reckon with the living, the chemical cycles of matter, etc. The complexity of the Earth system and the

\footnotetext{
${ }^{46}$ Some climatologists, physicists, are opposed to geoengineering precisely because their models only represent the physical parts and they are aware that they neglect important aspects. I would like to thank Hélène Guillemot for drawing my attention to this point.
} 
epistemological limits that result from it annihilate the confidence and optimism of the Prometheans. If there is Gaian geoengineering, it will be presented as more experimental, more on the side of the tinkering of a black box, than the fine and meticulous repair of a well-adjusted and well understood mechanism. Finally, the power to act is in Gaia's hands, and no longer in the hands of engineers and physicists: humans can intervene on Gaia, but in the end, these interventions will be presented as environmental acupuncture rather than as heavy surgery - we can only help Gaia to 'cure herself'.

The whole question then becomes what these three conceptual differences lead with in practice. Is the chasm so large between Lovelock's acupuncture needles, stimulating plankton - which, as we recall, are myriads of $200 \mathrm{~m}$ high concrete pipes and about ten meters diameters spread throughout the world's oceans - or Crutzen's careful chemical aerosols and the confident and winning aerosols of Lowell Wood and other Prometheans? It can be argued that this is not the case. All the important reasons that led to concern about Promethean geoengineering are entirely intact in the case of Gaian geoengineering. As Mike Hulme has brilliantly shown, these techniques are undesirable, since, by acting on a global scale they leave intact the important problem of local-regional climate change, not to mention ocean acidification. They are ungovernable given the colossal geopolitical and diplomatic challenges they raise and they are inaccessible (since the unexpected effects of these techniques will lead to endless experiments) ${ }^{47}$.

Moreover, by perhaps over-playing the explicit oppositions between Gaia and the Promethean spaceship, we obliviate certain elements of historical continuity. As with the Prometheans, the short-circuit of democratic debates and the relativisation of human rights was seen by Lovelock as an obligatory step in crisis situations $^{48}$. The strict opposition of philosophies of nature such as the one I presented can be grounded in the explicit discourses of certain scientists, and such a caricatural opposition is also useful for the sake of rendering visible distinctions and ways of thinking. But of course this perhaps caricatural opposition ought to be nuanced since any position between the two poles can exist.

Because of its apparent opposition to the Promethean discourse, and its historical association with environmentalism, the discourse legitimising geoengineering based on a systemic and Gaian conception of the Earth is less likely to generate immediate criticism from a wide audience, as the Promethean discourse could do. And, given current trends, it is likely to grow and amplify. Indeed, it is quite symptomatic that the workshop in which this paper was originally presented included a contribution that partly defends geoengineering based on IGBP's concepts.

If this article could be useful, it would be by drawing attention to the emergence of this discourse. Anyone who wishes to oppose the deployment of geoengineering can no longer reject it monolithically as the emanation of climate wizards who are too locked into outdated conceptions of nature. In other words, philosophies of nature will not serve as arguments on the basis of which to reject or accept geoengineering. If they are to have a role, and if there is still philosophical work to be done, it is undoubtedly on how these philosophies of nature lead to changes in the categories of geoengineering (SRM/CDR; global/local, etc) and their

\footnotetext{
${ }^{47}$ Hulme, Op. cit., 118-119.

${ }^{48}$ The revenge of Gaia, op. cit.
} 
deployment modalities ${ }^{49}$. If arguments based on general conceptions of nature are no longer sufficient to win the debate, we must give full weight to concrete governance and geopolitical issues highlighting the impossibility of managing such techniques, to scientific studies showing the risks and uncertainties associated with the deployment of geoengineering, to epistemological analyses revealing the limits of our knowledge on how these techniques work, to existing legal resources mobilised to support ongoing experiments. All these resources will undoubtedly prove to be more effective and relevant gateways to debate than the representations of nature conveyed by geoengineering advocates.

\footnotetext{
${ }^{49}$ Morton's book is quite remarkable in this respect.
} 